ISBN 978-81-936279-5-2

12th International Conference on Business, Education, Humanities and Interdisciplinary Studies

(BEHIS-18)

Zagreb (Croatia) May 11-12, 2018

\title{
The Guidelines Improving Quality of Online Businesses and Services
}

\author{
Jie Li and Dr. Watchara Yeesoontes \\ Graduate School of Business Administration, Kasem Bundit University, Bangkok, Thailand
}

\begin{abstract}
The purpose of this study is to investigate the online business websites and the quality of service that affect consumer behavior. There is the vine blowing of the Chinese online shopping. This study is based on quantitative. The collected data is based on a questionnaire and data is analyzed by means of percentage, mean and t-test of One-way Anova, and regression correlation. The study indicates that the majority of respondents were female aged of 21-40 years and they are undergraduates and the company employees and their monthly income equivalent to 10,000 - 15,000 THB. By using online business websites, purchased products are cheaper than purchased from real store shops and it is favorite ease of using for buying on a regular basis. There is search on demand by using of websites and customer service online order about in 500-2,500 THB. The quality of service provided through the online business websites is the overall average and important is improvement in quality and reliability at a high level. Hypothesis testing results show the confidence level, level of attention and customer response level are very high. There are personal factors of age, average income by different professions effect on the quality of service differently. The quality of service influences on consumers by using the service through their online business through websites. The test of results by using regression statistics showed that quality of service is done wherever have a problem can be ordered at any time and by using online website service is convenient and also influences on consumer behavior. There are recommendations in term of improvement of advanced equipment and services from online business service providers and provide quickly and accurate knowledge to employees in order to the benefits of customers to build credibility and confidence in providing services.
\end{abstract}

Keywords: Consumer, behavior, quality of service, website services, online business, etc.

\section{Introduction}

Network Technology This is a large network that connects to the world. It is a large online society that communicates with images, audio and text via internet-enabled tools. Online sales of goods and services. This reduces the time, distance and transaction costs. The price is lower than the market. But there are problems. About the business selling products and services through online. It is a scam finder. Receiving an item does not meet the ad. Personal Information Security And credit card information Do not see the product before ordering or ordering, etc. Which comments. Of the people mentioned above that the National Bureau of Statistics has come. It is useful to study more information. At the same time, consumers' attitudes will be an important part of getting to know the opinions. Consumers have to sell their products and services online. There are currently no statistics from any agency. The number of consumers' attitudes toward this type of service is discussed. It is the source that educators are interested in learning about consumer attitudes towards the business of selling goods and services through online. 


\section{Purpose of Study}

1. To study consumer behavior through the online business website.

2. To study the quality of service that affects consumer behavior through the online business website.

\section{Scope of Study}

1. Content In the study of the development of online service quality of online business, based on the concept of consumer behavior. Quality of service Trust / credibility Confidence What can be tangible? Attention Customer Response

2. Population Education from the population The Chinese are buying online products from the web. In the period from December 2017 to January 2018

3. Duration This study was conducted during December BE2560 - February BE 2561.

\section{Concept Framework}

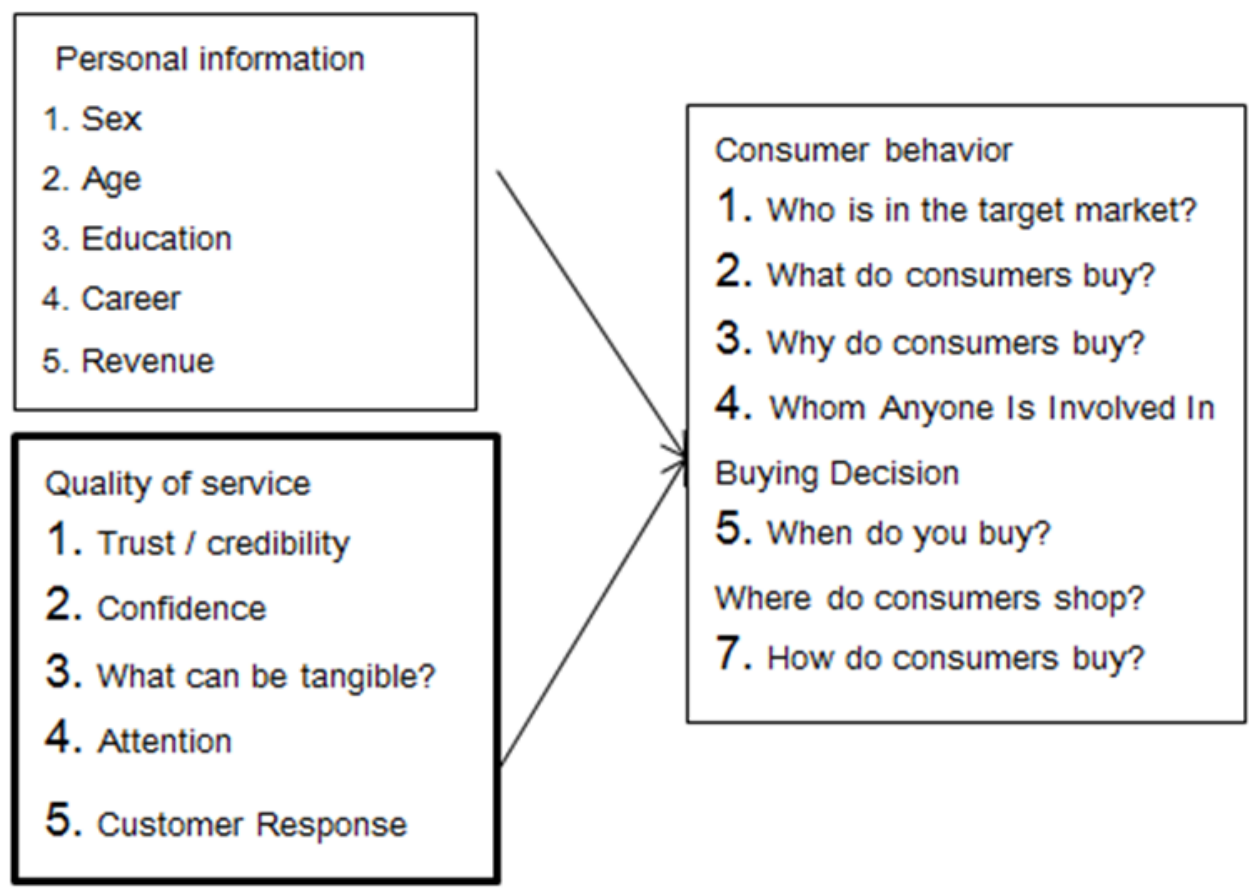

\section{Tools used in the Study}

Quantitative study Use the query as a tool. And to gather information. The Chinese made online auctions from 385 webs of vines.

\section{Data Collection Method}

The study was conducted. The purpose of this study was to provide the participants with the answers. And give it to the sample.The method of data collection is the questionnaire was distributed to 385 Internet consumers. The questionnaire was then used to verify the accuracy of the questionnaire. And continue processing. 


\section{Data Analysis}

Data analysis The questionnaire was analyzed by computer program bymeans of Percentage and Mean by Microsoft Excel, a program for creating pie charts and bar charts. Bar chart with descriptions of the results from the chart presented for analysis of the characteristics of the variables.

\section{Research Results}

The majority of respondents were female aged 21-40 years. Undergraduate / Junior / Equivalent Monthly income 10,000 - 15,000 baht and a career as a company employee.Consumer Behavior in Using Online Business Website Products purchased from online are cheaper than purchased from real stores. Ease of use Buy a favorite on a regular day. On-demand search using the website and customer service. Order Online 500-2500 Baht Quality is provided through the online business website. On average, the importance level is very high. We focus on reliability / reliability. Keeping customer information confid Research Resultsential Confidence Knowledge in the service. What can be tangible? Price compared to quality Attention Can contact immediately if the problem. Customer Response After-sales service

\section{Hypothesis Testing Results}

- Hypothesis 1. Different personal factors affect the behavior of consumers who use the service through different online business websites. The ANOVA statistic showed that personal factors of age, education level, occupational income, affecting the consumer behavior that is used through different online business websites.

- Hypothesis 2. Quality of service influences consumer behavior through the online business website. The results of the tests using Regression statistics showed that quality of service issues can be ordered at any time. Can contact immediately if the problem. And the service is convenient. Influence the consumers who use the service through the online business website.

\section{Discussions}

From the study. The quality of service through the website of the online business. The participants discussed the following issues.

1. Personal factors that vary with consumer behavior using the services through the site's online business consists of different age, education level and household income per month, consistent with different. Panuwat ratanapadit (BE.2555) study Factors that affect the success of your online business. It found that age, education level and average monthly incomes affect the success of your online business.

2. Different careers correspond to pongsak kongsub (BE.2552) study. Factors that affect the marking ADSL Internet service provider Bangkok. It found that the occupation affects the selected Internet service providers.

3. Service quality is affecting consumer behavior using the services through the website of the online business. The physical address is average overview on many levels is consistent with studies of the rain sayfun ratpitaktum (BE.2558) the subject of the service quality and brand image that influence willingness to use broadband Internet services, found that most respondents gave priority to the physical extreme levels. Is the product can be ordered at any time.

4. aspects of care overview the average level is very consistent with the work of Villa sayfun ratpitaktum (BE.2558) handle the subject of service quality and brand image that influence willingness to use broadband Internet services, found that most respondents give priority attention to the overall level is able to contact immediately if a problem occurs. And the service process as the most important story. 


\section{Suggestions from the Study}

From the study. Guidelines for improving the quality of online service use of online businesses. The researcher has suggested the following benefits.

1. trust / credibility Online Business Service Providers The importance of the accuracy of the service through the website of employees to ensure the reliability of the service.

2. Confidence Online Business Service Providers Customers should be aware of the importance of providing services to their customers.

3. What can be tangible? Online Business Service Providers It should focus on the supply and improvement of equipment, tools to provide modern services.

4. Attention Online Business Service Providers Should pay attention to the services that take into account the benefits of the customer to express the attention to the user.

5. Customer Response Online Business Service Providers Should pay attention to the speed of service to meet customers on time.

\section{Recommendations for Further Study}

The following study may employ qualitative studies, such as observational experiments. Or other methods. To get more in-depth information. This will be useful for planning business development.

\section{References}

[1] Pungsak kongsub .(BE2552). Factors affecting selection of ADSL internet service providers in the area. Bachelor's Degree College Buapipit Business School

[2] Panuwat rattanadit (BE 2555). Factors That Affect Online Business Success Faculty of Business AdministrationRajamangala University of Technology Thanyaburi

[3] Saifun ratpitaktum (BE.2558). Quality of service and brand image influences the intention of using broadband internet. Master of Business Administration, kasembundit university

[4] Colla\&Lapoule.(2012). Online business in grocery stores in France Parasuraman, A., Zeithaml, V. A. \& Berry, L. L. (1998). SERVQUAL: A Multi-item Scale for Measuring Consumer Perception of Service Quality. Journal of Retailing, 64(1), 12-40. 